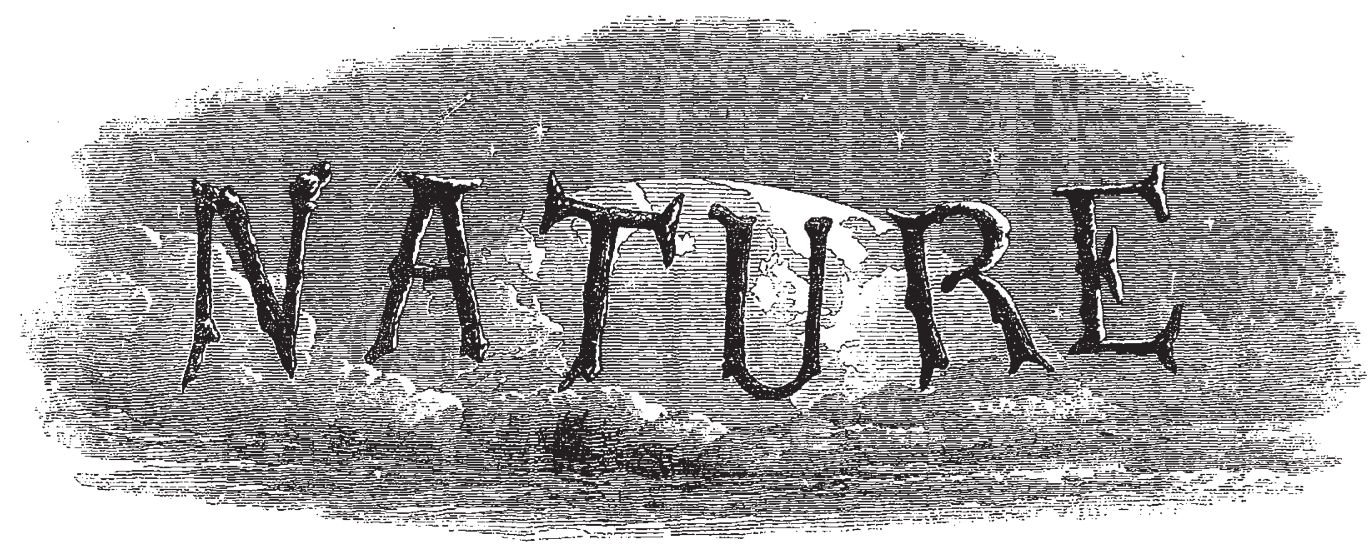

A WEEKLY ILLUSTRATED JOURNAL OF SCIENCE

"To the solid ground

Of Nature trusts the mind which builds for aye."-WorosworTH

THURSDAY, MAY 4, 1876

\section{THE PROGRESS OF THE LOAN} COLEECTION ${ }^{1}$

$\mathrm{T}$

$\mathrm{HE}$ investigation of the nature of those forces by which the material world is ceaselessly being moved and transformed, enlists in our day the energies of a host of scientific workers. It would be hard, perhaps, to mention a department of natural science for the study of which a good knowledge of the fundamental principles of what we now term physics is not at least a valuable aid and qualification, if not indispensably requisite. To the geologist and the biologist, no less than to the astronomer and the chemist, will such knowledge seem imperative. Considering the widespread ramifications of this division of science, it is not wonderful that the apparatus belonging to it should occupy so large a share of the available space in the present collection.

The remark formerly made, that much of the interest awakened in this loan collection will centre in its historical element -in the primitive forms of apparatus that represent, in some sort, the germs of some great development of scientific thought-holds good for the departmenis of which we propose now to take a brief survey in continuation of our last week's article. On entering the room devoted to physics iexclusive of electricity and magnetism), aftention is drawn to some agedlooking apparatus on the right. These are the celebrated original Magdeburg hemispheres of Otto von Guerické. They were exhibited by him in 1654 before the Princes of the Empire and the foreign ministers assembled at the Diet of Ratisbon. The force of two teams, each consisting of a dozen horses, made to pull in opposite directions (a portion of the rope is shown) was insufficient to separate the exhausted hemispheres. It was shorly after this date that the Burgomaster of Magdeburg heard of Torricelli's great discovery. The original air-pump of Otto von Guerické is also exhibited. It consisted of a globe of copper, with a stop-cock, to which a pump was fitted. The pump-barrel was entirely immersed in water to render it air-tight. The improvements

$$
r \text { Continucd from vol, xiii. p. } 505 .
$$

in the air-pump by Boyle and Hooke, Papin, Hawksbee, and others, can be followed by the actual instruments they made. Among modern improved methods of producing a vacuum, is the pump of M. Deleuil, in which the pistons are solid cylinders of considerable length, without packing or lubricants, and rot fitting tightly in the tubes. The internal friction of the air in the narrow space is so great that the rate at which it leaks into the exhausted part of the vessel, is not comparable with the rate at which the pump is exhausting air from the receiver. In the well-known air-pump of Sprengel, air is drawn from the vessel to be exhausted into a vertical tube, through the descent of small successive portions of mercury in the latter. Thilorier's apparatus for liquefying carbonic acid, the apparatus used by Dr. Andrews in his researches on continuity of the gaseous and liquid states of matter, and a small model of $M$. Colladon's new air and gas compressor used for the St. Gothard tunnel, may also be noticed here.

The musical commencement of sound is generally put at about thirty-two (single) vibrations, and the upper limit of audition at about 73,000 . Here will be found apparatus illustrating both extremes; including two organ pipes, the individual sounds of which are inaudible, but whose resultant tone or beat is within the limits of hearing. Helmholtz's double siren, and various other instruments connected with his invaluable researches on sound, will repay examination. Among musical instruments we may note some models of ancient Egyptian pipes, from the British Museum and that of Turin ; an enharmonic harmonium, tuned according to the division of the octave into fiftythree equal intervals; and the first of the now generally adopted upright pianofortes patented by Robert Wornum in I8Ir. Mr. Baillie Hamilton contributes a series of apparatus illustrating very instructively the progress of the Æolian principle. The velocity of transmission of sound in water was experimented on by Colladon, on the lake of Geneva, in 1826 , and again in $184 \mathrm{r}$, and some of his apparatus is shown in the present section. With the long tube like a speaking trumpet, it is possible, in calm weather, at the distance of more than a hundred kilometres, to hear the strokes on a bell of half a ton weight immersed in the water. Once more, the apparatus is to 
be seen by which Prof. Tyndall recently illustrated the reflection of sound by heated air or vapours; these, being made to stream up through six openings in the long chamber through which the sound is directed, are effectual in stopping its progress.

Of historical interest in the section of Light are some early stereoscopes, comprising that of Sir David Brewster; a camera-obscura said to have belonged to Sir Joshua Reynolds (which, when closed, has the form of a large folio leather-bound book), the original form of Brewster's kaleidoscope made by Bate, in $18 \mathrm{I} 5$, the first heliostat, invented by Gravesande, \&c. The vigour of the young science of spectroscopy is indicated by the fine array of instruments belonging to it, constructed by Steinheil, Browning, and others. There is shown the spectro copic apparatus which Sir John Herschel used in photographing actions of different parts of the spectrum, and in his investigations on some supposed new elements. For illustrating the theoretical side of the subject of polarised light, various forms of instrument have been devised, the most comprehensive of which is known as the wave machine of Wheatstone; its object is to exhibit the results of the combiration of various kinds of vibration meeting at various phases. Instruments based on the three different methods of producing plane polarisation are exhibited; and the various phases of rotatory and other polarisation can be shown simultaneously by means of an instrument which was invented inclependently by M. Mach and Mr. Spottiswoode. It is known that Wheatstone invented a "polar clock," based on the fact that the light from certain parts of the sky is polarised, and the plane of polarisation depends on the position of the sun; this is included in the collection. It would take too long to refer in detail to the now numerous varieties of photometric apparatus, or the apparatus for observing phosphorescence, fluorescence, and other phenomena connected with light. Several specimens exhibited of the enigmatical radiometers recently devised by $\mathrm{Mr}$. Crookes will doubtless excite lively interest and speculation. In the photographic collection is the first known photograph on glass, taken on precipitated silver chloride by Sir J. Herschel; also the second daguerreotype obtained by Daguerre in 1839 . The Woodbury and other processes are fully illustrated.

In the Heat department we cannot allow ourselves to linger at the fine collection of thermometric and other iristruments. Among them is a milligrade thermometer, in which the interval between the freezing and boiling points of water is divided into one thousand degrees; it obviates the use of fractions. Wedgwood's pyrometer and Lavoisier's calorimeter are here; and many will feel interested in such apparatus as that by which Tyndall conducted researches on radiant heat, Regnault, De la Rive, and Marcet on the specific heat of gases, or Favre and Silbermann on the heat disengaged in combustion.

In the room devoted to Chemistry we come upon some old apparatus which is of the simplest and even the rudest character; it is a part of that with which John Dalton carried on his classical researches. Most of it was made with his own hands, and the articles here exhibited are chosen as illustrating this fact, and as indicating the genius which, with so insignificant an equipment, was able to produce such great results. The study of pneumatic chemistry was much advanced by the experiments of Black and Cavendish. Black showed that the difference between the caustic and mild alkalies was that the latter contained fixed air, a kind of air identical with that obtained from fermenting liquids. Cavendish pointed out the difference between inflammable air, which we now call hydrogen, and fixed air, now known as carbonic acid gas. Black's pneumatic trough and balance, and Cavendish's balance, are among the collection. The latter is rude in exterior but of singular perfection. Here, also, is the balance, belonging to the Royal Institution, which was used by Young, Davy, and Faraday. The researches of Faraday on the condensation and liquefaction of gases are well known, and one may here see the apparatus he employed, along with a number of the original tubes containing gases which he liquefied. Thomas Graham's apparatus, also exhibited, is remarkable, like that of Dalton, for the contrast between its simplicity and the great results that were achieved by means of it. The amateur or professional chemist will doubtless receive not a few happy hints in inspection of the large variety of apparatus connected with qualitative and quantitative analysis ; and the com. prehensive collection of chemicals contains many novel. ties. We further note some of the apparatus that Messrs. Lawes and Gilbert have used in their important researches in agricultural chemistry, and they exhibit a case of casts of white Silesian sugar-beet illustrating the influence of different manures on the amount of produce and on the percentages of dry matter and sugar in the roots. The great chemical industries of this country, in fine, are well represented by models of manufactories and by products.

Coming to Biology, we may notice first an interesting collection of old microscopes. Here is the silver microscope that was used by Anthony von Leeuwenhoek, the Dutch philosopher, and probably made by him; also the microscope used by Sir W. Hooker, in his description of the British Jungermannieæ, \&c. The microscopes of Dawson Turner, Robert Brown, Muschenbroek, and others, are also included. There is a compound microscope invented and constructed about the year I590, by Jansens, the inventor of the telescope. This object, with its tin tube, is one of the most interesting things in the Collection. It is instructive to compare these instruments with their modern neighbours, of which there is a large variety.

The older physiologists obtained only qualitative results from their experiments; but the present generation has witnessed a remarkable advance in the application of instruments of precision to the quantitative determination of the effects of physiological processes. From this point of view a singular interest attaches to the muscle balance, constructed and used just forty years ago, by the eminent anatomist and physiologist who laid the foundations of animal histology. It is intended to demonstrate that muscular contraction takes place in accordance with the laws of elastic bodies, and it may be regarded as the first of the class of instruments referred to. The department contains a rich collection of such instruments; and no better illustration could be taken than the apparatus by which M. Marey has so successfully investigated the phenomena of animal locomotion and other physiological movements. The study of physiological optics has been 
greatly cultivated in Germany, and the instruments connected with it (whose nomenclature, by the way, seems unusually bristling and difficult) offer many novel points for consideration. The mechanism of circulation and respiration in the animal subject is studied by means of a variety of delicate apparatus, and we note also some good schematic representations in which the movements are reproduced mechanically. The anatomist and histologist will find many beautifully prepared specimens from animal and plant life.

Leaving the biological section we enter that of geography, geology, and the allied sciences. Here the instruments used by the late Dr. Livingstone in his last journey possess a melancholy interest; they comprise a pocket chronometer, a sextant, hypsometrical boiling apparatus, and three thermometers. Specimens are shown of the dredging, sounding, and other apparatus that have been used on board the Challenger, the Porcupine, and other exploring vessels. The collection of maps is a large one; in it will be found a selection designed to illustrate the progress of cartography and surveying in India, the maps of the Geological Survey of this country, \&c. ; also the MS. maps of Livingstone, Burton and Speke, Baker, Stanley, and others. In a glass case may be observed several open log-books. One is Capt. Cook's log of the Endecrour in his voyage round the world (1768-7I), another is that of one of his later voyages; another, the $\log$ of the proceedings of the Bounty, including an account of the mutiny. The subject of geology is largely illustrated by sections, maps, models, and specimens. We only note here the illustrations of the recent Sub-Wealden boring. There are numerous fine models in iliustration of crystallography, and one of the goniometers exhibited is that of the Abbé Hauy. Among the objects connected with mining may be noted the apparatus constructed by Sir Humphrey Davy in his researches on the safety lamp.

The section of Applied Mechanics, which we have left to the last, might well claim a separate paper or a series of such. We can do no more than briefly refer to the collection of James Watt's models, which indicate, e.g., the progress of his thoughtful labour in connection with the idea of separate condensers, and the expansive working of steam. In Watt's first engine great difficulty was experienced in fitting the piston accurately to the cylinder. Such difficulties exist no longer; and a remarkable example of the skill now attained in metallic constructions is afforded in the fine surface plate lent by Sir J. Whitworth; this is probably the closest approximation to an absolutely plane surface that has yet been realised. Finally, the old "Rocket" constructed by Stephenson in 1829 , and the original engine of Henry Bell's steamboat, appear in this collection, the venerable quondam precursors of a great social revolution.

\section{PREFEVALSKY'S MONGOLIA}

Mongolia, the Tangut Country, and the Solitudes of Northern Tibet. By Lieut.-Colonel N. Prejevalsky, Translated by E. Delmar Morgan, F.R.G.S. With Introduction and Notes by Colonel Henry Yule, C.B. (Sampson Low and Co., 1876.)

WE have had occasion once or twice to refer briefly to Col. Prejevalsky's travels in Eastern High Asia, and some of our readers may have seen more or less detailed notices of his journey in the German and English geographical journals. These have been sufficient to show that the narrative of the Russian officer is of unusual value, and we are therefore thankful that not much time has been lost in making it accessible to the English public, to which Russian is practically an unknown tongue. The two volumes before us, however, contain only Col. Prejevalsky's general account of his expedition; and we regret that there seems to be no intention of making the special scientific results accessible to English readers. Judging from what is contained in the two volumes before us, these must be of the highest importance, and we hope that by some means they will be made known to English men of science.

The present translation has been brought out with great care. Mr. Delmar Morgan has put the narrativa into clear and idiomatic English, which, we have reason to believe, faithfully represents the original Russian. $\mathrm{He}$ has, moreover, added to the value of the narrative for English readers by numerous supplementary and foot notes. We consider that both Col. Prejevalsky and the English reader are particularly fortunate in having the advantage of Col. Yule's knowledge to supplement and correct the original narrative. In an introduction he connects the journey of the Russian officer with those of previous explorers in Central and Eastern Asia, and especially with that of the well-known Huc and his companion Gabet. Considerable discredit has been thrown on the narrative of $\mathrm{Huc}$, but Col. Yule shows that in the main it may be regarded as trustworthy, allowance being made for the missionary's love of exaggeration and his desire to produce effect. Prejevalsky's journey from Pekin to the south-west into Tibet coincided to some extent with that of Huc, and the former on several occasions impagns the accuracy, if not the veracity, of the latter. Those who are familiar with the old Abbés delightful narrative will be glad to know that so great an authority as Col. Yule thinks that after all he is in the main trustworthy. Col. Yule's numerous notes will, moreover, be found to add much to the value of the work, both as supplementary to the main narrative and as corrective of occasional statements by Col. Prejevalsky arising from imperfect knowledge or rashness. This narrative Col. Yule shows, is an additional confirmation of the remarkable accuracy of that of Marco Polo.

The starting-point of C@l. Prejevalsky's expedition was the town of Kiakhta, on the border of Siberia and Northern Mongolia, from which the small party set out in November, I870, and returned to it after having cone three years' hard and fruitful work, in October, 1873 . The expedition seems to have been essentially a Government one, sent out at the instigation of the Russian Geographical Society. It is, therefore, difficult to understand how Col. Prejevalsky should have been so seriously hampered from want of sufficient funds. Yet so it was; the resources at the leader's command were a mere pittance as compared with the magnitude of the undertaking. The entire party consisted only of the Colonel, a companion, and two Cossacks, and the instrumental equipment was the most meagre possible. All things considered, it is marvellous that the results achieved were so many and so valuable. From Kiakhta the party went by Urga across the desert of Gobi, probably the dreariest desert in the world, to 